\title{
Validity, Reliability, Intra-rater Instrument Parameter Teaching Factory and Learning Outcomes of Industrial Clothing
}

\author{
Ratna Suhartini ${ }^{1, *}$ Ekohariadi $^{2,4}$ Luthfiyah Nurlaela $^{3}$ Urip Wahyuningsih $^{1}$ \\ Yulistiana ${ }^{1}$ Yuhri I. Prihatina ${ }^{1}$
}

\author{
${ }^{1}$ Fashion Design Vocational Program, Universitas Negeri Surabaya \\ ${ }^{2}$ Department of Informatics Engineering, Universitas Negeri Surabaya \\ ${ }^{3}$ Home Economic Department, Faculty of Engineering, Universitas Negeri Surabaya \\ ${ }^{4}$ Postgraduate Study Program, Universitas Negeri Surabaya \\ *Corresponding author. Email: ratnasuhartini@unesa.ac.id
}

\begin{abstract}
The research aims to review the quality instrument of teaching factory parameters and learning outcomes instruments on fashion industry competence, especially internal consistency (Cronbach's alpha), reliability of retesting (Pearson correlation), and construct validity of existing parameters. Respondents were school principals and teachers involved in teaching factory management in a vocational high school for the Fashion Design skill program that taught factory learning, namely 30 people, while the research sample for testing the learning outcomes instrument was 90 students. Data collection instruments used questionnaires and observation sheets. Data analysis techniques using. Data analysis using Pearson or Product Moment, Cronbach Alpha Intraclass Correlation Coefficients (ICC). The results showed that the teaching factory's Corrected Item Total Correlation parameter was positive and $>0.3$, so it was declared valid. Cronbach's alpha value of all dimensions of the teaching factory parameter is greater than 0.6 , so that it can be declared to have good reliability. The learning outcome instrument is valid because the Corrected Item Total Correlation is positive and $>0.3$, and Cronbach's alpha value is greater than 0.6 so that the learning outcome variable is declared to have good reliability. The measurement of the level of agreement between raters shows an average agreement between raters of 0.832 , while for one rater, it is 0.712 . The results show the average agreement between raters is 0.894 , while for one rater, it is 0.809 . The research aims to review the quality instrument of teaching factory parameters and learning outcomes instruments on fashion industry competence, especially internal consistency (Cronbach's alpha), reliability of retesting (Pearson correlation), and construct validity of existing parameters. Respondents were school principals and teachers involved in teaching factory management in a vocational high school for the Fashion Design skill program that taught factory learning, namely 30 people, while the research sample for testing the learning outcomes instrument was 90 students. Data collection instruments used questionnaires and observation sheets. Data analysis techniques using. Data analysis using Pearson or Product Moment, Cronbach Alpha Intraclass Correlation Coefficients (ICC).
\end{abstract}

Keywords: Teaching factory fashion design parameters, validity, reliability, inter-rater

\section{INTRODUCTION}

Teaching factory is the application of industrybased learning. Teaching factory is widely applied in vocational high schools. In the implementation of the teaching factory, the practice results are products that are ready to be sold in the market. Products have industry standards. The learning process is industry standard, and the practice space reflects the work area in the industry. In the Vocational High School curriculum, some subjects can apply the learning, namely subjects that produce products or services. Products can be in the form of finished products or semi-finished products. The curriculum of the Fashion Design study program includes industrial fashion subjects in class XI and class XII.

There are teaching factory parameters in the learning process, which are useful as a reference in the implementation of learning. These teaching 
factory parameters are interconnected with one another. Teaching factory parameters include management, human resources, workshops or practice rooms, training learning patterns, products or services, marketing promotions, industrial relations. While the learning outcomes of industrial clothing refer to the $6 \mathrm{M}$ teaching factory learning, namely receiving orders, analyzing orders, stating readiness to work on orders, working on orders, quality control, and submitting orders. The teaching factory parameter is the instrument in this study. The learning outcome instrument refers to the learning process following six steps. While the learning outcomes of industrial clothing refer to the $6 \mathrm{M}$ teaching factory learning, namely receiving orders, analyzing orders, stating readiness to work on orders, working on orders, quality control, and submitting orders. The teaching factory parameter is the instrument in this study. The learning outcome instrument refers to the learning process following six steps. While the learning outcomes of industrial clothing refer to the $6 \mathrm{M}$ teaching factory learning, namely receiving orders, analyzing orders, stating readiness to work on orders, working on orders, quality control, and submitting orders. The teaching factory parameter is the instrument in this study. The learning outcome instrument refers to the learning process following six steps.

A research instrument is a tool used to measure the observed natural and social phenomenon [1]. Research instruments include teaching factory instruments known as teaching factory parameters and industrial clothing learning outcomes. Before the instrument is used to collect data, it is necessary to test the validity, reliability, and inter-rater. This study was conducted to examine the quality of the instrument, the factors that influence the learning outcomes of industrial clothing through factory teaching-learning. Instrument reliability was assessed by internal consistency (Cronbach's alpha) and retest-test coefficients (Pearson correlation). The research instrument that will be used to collect data about student learning outcomes and teaching factory parameters is a questionnaire with a scale of 1 to 4 .

Instruments should be easy to administer, have simple questions, be easy to examine, easy to analyze, collect multicenter data, and be suitable for using 'pre' and 'post' interventions (i.e., avoid retrospective questioning and relying on memory). Various methods were used to test the reliability and validity of the questionnaire. 'Content validity' aims to ensure that the instrument's content covers the domain of relevance (for example, the extent to which a test adequately tests the domain of information, knowledge, or skill it purports to measure) and is determined primarily by a judgmental expert. 'Face Validity' allows the respondent to describe in his or her own words what he or she thought was asked or not asked (i.e., ensuring the question was interpreted as intended). This is a particularly useful approach for identifying areas of ambivalence and is important for researchers conducting validity procedures using a structured face-to-face interview approach to explore the perceived meaning of the questions. 'Reliability' aims to ensure that the questionnaire is reproducible through measures of internal consistency with groups of similar questions and repetition, ensuring the consistency of the questionnaire over time. In addition, the feasibility of using the questionnaire should be tested in groups similar to which it was designed [2]. This study aims to assess the validity and reliability of a short questionnaire designed to measure the factors that influence the learning outcomes of industrial clothing in teaching factory learning. The aim is to assess the validity of the content, face the validity, internal reliability, to produce a validated instrument for use in research. Questionnaire development in the form of a draft questionnaire was prepared after a literature search (and subsequent review of the appropriate questionnaires [3][4][5] and assessment of learning outcomes. The teacher checked the draft work questionnaire. And the manager of the teaching factory for content and clarity before validity testing.

\section{LITERATURE REVIEW}

\subsection{Validity}

[6] state A valid measure yields a correct estimate of what is being assessed. [7] define validity as referring to accuracy and precision. A valid measure yields an accurate estimate of the construct being measured. There are three strategies to obtain validity, namely content-related validity, construct-related validity, and criteria-related validity. [8] says that content validity refers to how the items in the test represent aspects of the role or job. [8] states that construct validity is related to the extent to which the test measures certain constructs or characteristics. The underlying phenomenon, known as the construct, is designed for existing within the item [9]. Content validity involves evaluating a new survey instrument to ensure that: it covers all important items and eliminates items that are not desirable to a particular construct domain [10][11]. Construct validity ensures that the instrument measures the intended construct and not irrelevant measurements [12]. Criterion-related validity is defined as the extent to which a score on one variable can be used to infer performance on the 
operational criteria of the independent variable [9][11][13].

Content validity refers to the extent to which an instrument covers all concepts. Content validity was assessed by checking the suitability between the teaching factory parameters and learning outcomes with the relevance taken in the literature by looking for the parameter factors included in the instrument being assessed. The search was developed to check the validity of the instrument content. One search resulted in teaching factory parameter factors described with meta-analysis and review only. The first step is a literature search to explain the theoretical basis of the teaching factory parameter concept. The theories assumed as teaching factory parameters include: management theory, human resource theory, workshop and layout theory, training learning theory, product and service theory, marketing promotion theory, industrial relations theory, and the theory of learning outcomes of industrial fashion making. The second step is the content validity of the validator, which identifies relevance concerning the teaching factory parameters using a meta-analysis and produces a review that is studied to find related factors that may be formed from the basic concept of the teaching factory parameter. The factors found are expected to be contained in the instrument used to assess the validity of the content.

Management factors are categorized into six related domains. The domains of teaching factory management content are financial administration (financial transaction records, financial reports, daily records, order, and billing management systems); organizational structure (organizational structure, SOP, legality of organizational structure); SOP performance and workflow ( SOP compliance with work units, personal understanding of SOPs, explanation of process flow); Leadership (understanding of school leaders about teaching factories, understanding of those in charge of teaching factories, teaching factory policy documents, motivation of school leaders); The impact of the teaching factory on the institution (impact on welfare, work culture, impact on education, impact on functional materials); Environment (stakeholder engagement, internal support, external support, community support). The workshop/practice space factor is categorized into six related domains. Domain on the content of the workshop/practice room in a teaching factory are equipment (number and type of equipment, proportion of equipment, condition of equipment, suitability of production and facilities); governance (SOP for using tools, inventory of tools, SOP for borrowing tools, SOP for storing tools); Space (space area, spatial planning, workflow, air circulation); MRC (person in charge of MRC, well planned and executed, there is an MRC card, according to standards and ready to use); layout (according to industry standards, layout design according to current conditions, K3, arranged according to level). Factors of training learning patterns are categorized into seven related domains. The domains in the content of the training learning patterns in the teaching factory are: lesson plans, LKS (product and competency-based learning, products are detailed into $\mathrm{KD}$, there is a jobsheet, assessment according to industry standards); Practical materials (available and are raw materials for the production process, from consumers, part of the sample making, part of the cost); Entrepreneurship (work is carried out according to stages, students are able to compete, students are involved in product targets, interact with customers); implementation of training (equipment and materials according to the production process, students are directly involved in the production process, target time, efficiency, production process, work rotation, work process according to industry); production base (products are objects that are ordered/sold, can be sold in the market, practical costs are part of production costs, industrial production processes); teaching activities (teachers teach according to their main duties, according to product innovation learning, complete work that has not been completed by students, cooperate and coordinate with industry); based on corporate culture (according to the work ethic in the industry, time discipline, procedural discipline, team work oriented). Promotional marketing factors are categorized into five related domains. The domains of promotional marketing content in the teaching factory are promotional marketing (having marketing promotions, implementing marketing promotion plans, running according to plan, supported by the availability of funds); communication media (optimally reaching the market, the institution's capability is known by the industry, there are job orders from the industry, job orders exceed the production limit); brochures/leaflets (have brochures, use them optimally, have leaflets, have a website); market reach (overseas, domestic, district, school environment); the person in charge of the teaching factory (there is a decree, the job description is carried out, SK relations with industry, there is a turnover). Product and service factors are categorized into five related domains. The domains of product and service content in the teaching factory are products for internal needs (standard 
quality, incidental quality standards, standard quality semi-finished products, according to competence); market acceptance (products can compete in the market, increased sales turnover, competitive bargaining prices, acceptable in the market): delivery (always on time, relatively low complaints, requires delivery time, requires customer satisfaction); quality (number of orders is close to production capacity, cost of goods is the same level of product, meets market acceptance, price is lower than production cost); quality control (product and quality results, pass defects, reject less than 5\%, reject more than 5\%). Human resource factors are categorized into five related domains.

The domains in the content of human resources in the teaching factory are: competence (have production experience, have worked in industry, have competency certificates, have products worked in industry); the number and suitability of human resources (there are 4 or more teachers, have the ability to build a market network, place people according to their competence, have competence in the garment sector); motivation (carrying out tasks with full responsibility, working hard on unfinished work, likes challenges and can solve problems, has the drive to make the teaching factory successful); innovation (having many ways to implement and integrate teaching factory in activities, supervise the implementation of work and work achievement, carry out work targets according to work achievements, carry out work targets according to the level of difficulty, plan, implement, and produce products in new ways); teamwork (supporting each other, very good, helping and strengthening each other, working optimally). Industry relationship factors are categorized into three related domains. The domains of industrial relations content in the teaching factory are: forms of cooperation (products and services are directly related to the job order quota industry, there is cooperation in products and services as needed, teacher internships); project work (based on industrial problems, the resulting product is a solution to the problem by considering the economic side, there are industrial visits, based on project work practices); technology transfer (there is technology transfer, there is a cooperation order, cooperation in the form of a consultant, there are experts from the industry to provide training); Learning outcomes factors are categorized into six related domains. The domains in the learning outcomes of industrial clothing in the teaching factory are: receiving orders (greetings, smiles and greetings, agile, polite in speaking, enthusiastic); analyzing orders (analyzing designs, analyzing materials, analyzing patterns, analyzing sewing techniques); declare readiness (willing to do the task according to the agreement, alert, diligent, independent); working on orders (making patterns: preparing patterns and sizes, breaking patterns according to design, appropriate pattern sizes, good pattern lines, cutting patterns: cutting patterns smoothly, cutting completely, straight cuts, cutting results according to patterns; bandling: according to type, mark banding, tie neatly, store neatly; sewing: stitches following pattern lines, stitches symmetrical stitches, stitches even, stitches neatly; finishing: neat seams, neat pressing, neat buttons, neat packaging); perform quality control (same pattern size, unwrinkled stitches, no defects in materials, neat packaging); submit orders (greetings, smiling greetings, submitting orders according to the condition of the goods, submitting orders in a timely manner, saying thank you).

\subsection{Reliability}

Testing for reliability is important because it refers to consistency across all measuring parts of the instrument [14]. A scale is said to have high internal consistency reliability if the scale items "hang together" and measure the same construct [14][15]."Reliability is related to the degree of consistency and stability of data or findings" [1]. A data is declared reliable if two or more researchers in the same object produce the same data. Instrument reliability was assessed using internal consistency and retest-test coefficients. Instruments with an internal consistency coefficient of 0.80 (total scale) or higher are considered adequate. The coefficient of the scale range must be at least 0.80 . Following [16], this is accepted as reasonable reliability. The retesttest coefficient should be 0.70 or higher, or if there is no total score, the retest-test range should be 0.70 or higher. Internal Consistency Reliability: To interpret the internal consistency reliability, the researchers used the alpha coefficient (Cronbach's alpha coefficient) / Kuder Richardson / KR20. Cronbach's alpha is often used and is the most acceptable and reliable method. [17] stated that the reliability of 0,60 is acceptable for newly built instruments or at an early exploration stage. According to [18], reliability of more than 0.8 is the most acceptable value, between $0.6-0.8$ is less acceptable, and a value is less than 0,6 is not accepted.

Meanwhile, according to [19], reliability of more than 0.94 is very good, $0.91-0.94$ is very good, 0.81 0.90 is good, 0.67-0.80 is not good, and 0.67 is bad. . [20], notes that an alpha value above 0.7 is acceptable. The most appropriate measure of reliability when using a Likert scale [21] [15]. 94 very good, 0.91-0.94 very good, 0.81-0.90 good, 
0.67-0.80 less good and 0.67 bad. [20], notes that an alpha value above 0.7 is acceptable. The most appropriate measure of reliability when using a Likert scale [21] [15]. 94 very good, 0.91-0.94 very good, 0.81-0.90 good, 0.67-0.80 less good and 0.67 bad. [20], notes that an alpha value above 0.7 is acceptable - the most appropriate measure of reliability when using a Likert scale [21] [15].

\subsection{Intra-Rater Reliability}

Intra rater reliability or the same observer reliability is used to assess the extent to which the same rater or observer provides a consistent estimate of the same phenomenon [22]. Intra rater reliability refers to the ability of the rater. Intra-rater reliability is as important as inter-rater reliability because if the first reliability is not safe, so is the latter [23]. The appraisal behaviour of the rater can be influenced by internal and external factors, which can lead to inconsistency of appraisal performance. for individual raters

Two types of statistical tests are often used to measure inter-rater reliability. Namely, the Intraclass Correlation Coefficient (ICC) is used for the ordinal, interval, and ratio data, and the Kappa Coefficient for nominal data. ICC is the ratio of variation between subjects (Between subject Variation (BSV)) to total variation (Within Subject Variation (WSV)). The ICC reaches a maximum value of 1 when the WSV reaches the lower limit of 0 . This assessment indicates that the variation in the data is not due to inconsistent raters. ICC proved to be a valid measure of inter-rater consistency.

\section{METHODOLOGIES}

The accuracy and consistency of the survey/questionnaire is an essential aspect of the research methodology. This research instrument was tested on three pilot schools. Content validity includes three teachers and one garment leader for validation purposes; an instrument with a scale of 14 was made. The validator selects an appropriate answer and provides notes that need to be changed or added to the instrument. Furthermore, the instruments are compiled, and the validation sheet is submitted to the validator to be assessed and given input. Validators provide feedback, input, and suggestions on variables, aspects, and indicators. The research respondents were principals, teachers. The research sample is students. Principals and teachers answered a questionnaire about the teaching factory parameters, while students were the research base used to assess learning outcomes. The principal, vice-principal of the curriculum section, deputy principal of the infrastructure section, viceprincipal of student affairs, vice-principal of the public relations section, and five teachers, filled the instrument teaching factory, a total of 30 people. In comparison, the student learning outcomes of 90 people were filled by six teachers. during the teaching factory learning process

The initial step of testing the research instrument is to test the validity of the content. The validator consists of 3 vocational school teachers and one leader of the garment industry. From the results of content validity, improvements were made, then the instrument was tested. Firstly, we tested the validity, reliability, and validity between raters. Then, test the validity, reliability using SPSS 23. Suppose the Corrected Item Total Correlation is positive and > 0.3 . In that case, the teaching factory parameter instrument is declared valid, Cronbach's alpha value of all dimensions has a value of $>0.6$, then the teaching factory parameter instrument is declared reliable. The test between raters uses the intraclass correlation coefficients (ICC) developed by Pearson (1901). This coefficient was developed based on the analysis of variance, but in some instances, the results have similarities with the alpha coefficient. ICC test principle: 1$)$. ICC coefficient value $>0.6$ or p-value \& alpha (0.05), the perception between researchers and data collectors is the same. 2) ICC coefficient value $<0.6$ or p-value $\&$ alpha $(0.05)$, the perception between researchers and data collectors is different. It means that the instrument has a reasonably high quality of stability. (Streiner et al., 2000). 3) The measuring instrument has adequate stability if the ICC between measurements is $>0.50$, high stability if the ICC between measurements is 0.80. (Strainer and Norman, 2000). 


\section{RESULTS}

\subsection{Content Validity}

The results of the instrument content validity of each variable are as follows: the management variable has weaknesses. Several indicators do not refer to the aspects to be assessed, namely: 1) Planning aspects, which are planned are teaching factories, not products to be sold; 2) Aspects of organizational structure, there is the legality of the division of labour (SK from the principal); 3) Performance SOPs include guidelines for working, facilitating work team supervision, being implemented consistently, and creating work efficiency; 4) Administration other than financial records, providing assistance services, reporting, and attendance. 5) leadership, apart from motivating, also needs to strengthen the existence of the institution.

Variable workshop/practice room, there is no suggestion and input from the validator. Thus the variable workshop/practice room can be tested for total item correlation. Variable Learning Patterns: There are several validator inputs, namely based on practice to become a production base. The marketing promotion variable does not have suggestions and input from the validator. The

\subsection{Teaching Factory Parameter Validity and reliability}

The results of the teaching factory parameter validity test using Cronbach alpha, in table 1 , shows that the question items in the teaching factory parameter variable are said to be valid because: Corrected Item Total Correlation positive sign and > 0.3 . Thus, all question items from the dimensions of Management, Workshop/Laboratory, Learning Patterns, Marketing Promotion, Products/Services, HR, Industrial Relations, all indicators can measure all dimensions of the teaching factory parameter variable. On this basis, all items meet the validity requirements and will be maintained on the scale and used in further analysis.

The calculation results show that the Cronbach alpha value of the teaching factory parameter experts validated the product or service variables in product planning, including product design, determining the number of products, setting product prices, and product benefits. The aspect of market acceptability, it is necessary to include new characteristics, in the delivery aspect, sentence adjustments with the term delivery, namely accuracy order until the product arrives, the order can be accepted flexibly, guaranteeing the product is delivered on time, and the product is following the order.

Meanwhile, product quality includes durability, reliability, product conformity with industry standards, and ease of use and repair. Variable Competency of human resources is the quality of work, skilled in teaching materials following the industry, and understanding the concept of production flow. Innovation is the workability of HR, including determining learning strategies, implementing learning, carrying out evaluations. At the same time, teamwork is communication skills, including communication with students, teamwork, industrial partners, and communicating teaching factory products to teaching factory managers. Revisions are made based on expert input. Improvements were made to terms in terms of instruments, indicators, and writing in terms of legibility.

variable is greater than 0.6 , so that variable teaching factory parameters are declared to have good reliability. It means the variables are related in good terms

\subsection{Validity and Reliability of Learning Outcomes Instruments}

The calculation results show the Cronbach alpha value in Table 2. indicates that the question items on the learning outcomes variable are valid because Corrected Item Total Correlation positive sign and > 0.3 . On this basis, all items meet the validity requirements and will be maintained on the scale and used in further analysis. The calculation results show that the Cronbach alpha value of the learning outcomes variable has a value greater than 0.6 , so that variable learning outcomes are declared to have good reliability. 
Table 1. The Validity of The Questionnaire Results That Have Been Tested Obtained All Valid

\begin{tabular}{|c|c|c|c|c|c|}
\hline Dimensions & Indicator & R & Description & Cronbach Alfa & Description \\
\hline \multirow{6}{*}{ Management } & Financial Administration & 0.55 & VALID & \multirow{6}{*}{0.829} & \multirow{6}{*}{ Reliable } \\
\hline & Organizational Structure & 0.62 & VALID & & \\
\hline & $\begin{array}{l}\text { SOP Performance and } \\
\text { Workflow }\end{array}$ & 0.43 & VALID & & \\
\hline & Leadership & 0.76 & VALID & & \\
\hline & $\begin{array}{l}\text { The Impact of Teaching } \\
\text { Factory on Intuition }\end{array}$ & 0.63 & VALID & & \\
\hline & Environment & 0.72 & VALID & & \\
\hline \multirow{5}{*}{ Workshop/Laboratory } & Equipment & 0.61 & VALID & \multirow{5}{*}{0.862} & \multirow{5}{*}{ Reliable } \\
\hline & Tool Use Governance & 0.5 & VALID & & \\
\hline & Room & 0.83 & VALID & & \\
\hline & $\begin{array}{l}\text { Management } \\
\text { Maintenance, Repair \& } \\
\text { Calibration (MRC) }\end{array}$ & 0.72 & VALID & & \\
\hline & Layout Workshop & 0.79 & VALID & & \\
\hline \multirow{7}{*}{ Learning Pattern } & $\begin{array}{l}\text { Learning Implementation } \\
\text { Plan (RPP) \& LKS (Job } \\
\text { sheet) }\end{array}$ & 0.74 & VALID & \multirow{7}{*}{0.771} & \multirow{7}{*}{ Reliable } \\
\hline & Practice Materials & 0.46 & VALID & & \\
\hline & Entrepreneurship & 0.45 & VALID & & \\
\hline & $\begin{array}{l}\text { Implementation of } \\
\text { Training }\end{array}$ & 0.4 & VALID & & \\
\hline & Practice Base & 0.66 & VALID & & \\
\hline & $\begin{array}{l}\text { Lecturer/Instructor } \\
\text { Activities }\end{array}$ & 0.49 & VALID & & \\
\hline & $\begin{array}{l}\text { Based on Corporate } \\
\text { Culture }\end{array}$ & 0.36 & VALID & & \\
\hline \multirow{5}{*}{ Marketing Promotion } & Marketing \& Promotion & 0.7 & VALID & \multirow{5}{*}{0.759} & \multirow{5}{*}{ Reliable } \\
\hline & $\begin{array}{l}\text { Communication Media } \\
\text { for Teaching Factory }\end{array}$ & 0.59 & VALID & & \\
\hline & $\begin{array}{l}\text { Brochures/leaflets/other } \\
\text { resourcer (website, CD, } \\
\text { etc) }\end{array}$ & 0.62 & VALID & & \\
\hline & Market Reach & 0.48 & VALID & & \\
\hline & $\begin{array}{l}\text { Responsible for Teaching } \\
\text { Factory }\end{array}$ & 0.36 & VALID & & \\
\hline \multirow{5}{*}{ Product/Service } & $\begin{array}{l}\text { Products for Internal } \\
\text { Needs }\end{array}$ & 0.48 & VALID & \multirow{5}{*}{0.792} & \multirow{5}{*}{ Reliable } \\
\hline & Market Acceptance & 0.66 & VALID & & \\
\hline & Delivery & 0.76 & VALID & & \\
\hline & Quality & 0.7 & VALID & & \\
\hline & Quality Control & 0.33 & VALID & & \\
\hline \multirow{5}{*}{$\mathrm{HR}$} & Competence & 0.36 & VALID & \multirow{5}{*}{0.85} & \multirow{5}{*}{ Reliable } \\
\hline & $\begin{array}{l}\text { The number and } \\
\text { suitability of human } \\
\text { resources to run }\end{array}$ & 0.78 & VALID & & \\
\hline & Motivation & 0.9 & VALID & & \\
\hline & $\begin{array}{l}\text { Innovation (benefit for } \\
\text { "user") }\end{array}$ & 0.63 & VALID & & \\
\hline & Teamwork & 0.83 & VALID & & \\
\hline Industrial Relations & Form of cooperation & 0.44 & VALID & 0.636 & Reliable \\
\hline
\end{tabular}




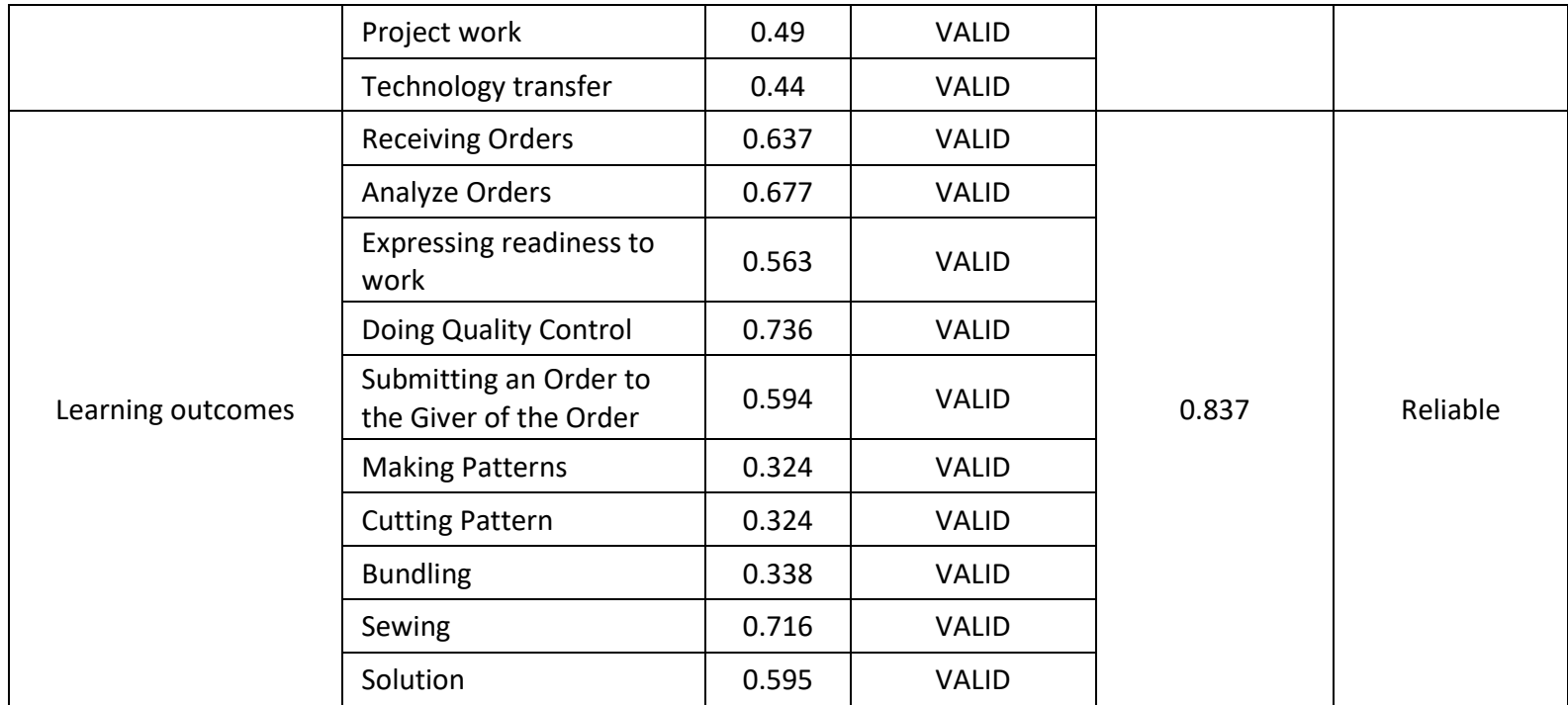

\subsection{Intra rater Reliability}

The measurement of the level of agreement between raters uses the IRR (Inter-rater Reliability) and ICC (Interclass Correlation Coefficient) coefficients to calculate the IRR coefficient using the formula proposed by [24]. The measuring instrument has adequate stability if the ICC between measurements is $>0.50$, high stability if the ICC between measurements is 0.80 . [25]. The analysis results show that the average agreement between raters is 0.832 , while for one rater, it is 0.712 . While the results of the inter-rater analysis of learning outcomes show the average agreement between raters is 0.894 , while for one rater, it is 0.809 .

Table 2. Intraclass Correlation Coefficient

\begin{tabular}{|l|r|r|r|r|r|r|r|}
\hline \multirow{2}{*}{} & \multirow{2}{*}{$\begin{array}{l}\text { Intraclass } \\
\text { Correlation }\end{array}$} & \multicolumn{2}{|c|}{$95 \%$ Confidence Interval } & \multicolumn{3}{|c|}{ F Test with True Value 0 } \\
\cline { 5 - 9 } & & Lower Bound & Upper Bound & Value & df1 & df2 & Sig \\
\hline Single Measures & $.712^{\mathrm{b}}$ & .504 & .842 & 5.940 & 35 & 35 & .000 \\
\hline Average Measures & $.832^{\mathrm{c}}$ & .670 & .914 & 5.940 & 35 & 35 & .000 \\
\hline
\end{tabular}

Table 3. Intraclass Correlation Coefficient

\begin{tabular}{|l|r|r|r|r|r|r|r|}
\hline & \multirow{2}{*}{$\begin{array}{c}\text { Intraclass } \\
\text { Correlation }\end{array}$} & \multicolumn{2}{|c|}{$95 \%$ Confidence Interval } & \multicolumn{3}{|c|}{ F Test with True Value 0 } \\
\cline { 5 - 9 } & & Lower Bound & Upper Bound & Value & df1 & df2 & Sig \\
\hline Single Measures & $.809^{\mathrm{b}}$ & .402 & .949 & 9.444 & 9 & 9 & .001 \\
\hline Average Measures & $.894^{\mathrm{c}}$ & .574 & .974 & 9.444 & 9 & 9 & .001 \\
\hline
\end{tabular}

\section{DISCUSSION}

The teaching factory parameter is a vital component in teaching factory learning. The interaction between the variables in the teaching factory parameters is very important if you want to achieve learning objectives. Management is a variable teaching factory whose main function is to ensure that everything related to achieving goals can be successful. Management in the teaching factory includes planning teaching factory activities, organizing, namely placing each manager/all human resources and resources owned by the school into each task, directing and supervising, namely supervising each work and production process and results. All indicators in management have corrected Item Total Correlation positive sign and $>0.3$. This means that all indicators on 
management variables are valid to be used as research instruments.

Human resources are teachers who act as managers and teachers. In addition, human resources have a major role in communicating and collaborating with the garment industry. This collaboration is in the form of training, technology transfer, and project work. Human resources manage learning so that students have skills and soft skills. The learning outcomes of this course are products that can be sold in the market. Therefore, the products that human resources and the garment industry have planned for marketing and promotion. Teaching factory learning activities are closely related between one variable and another, as described above. All indicators in the above variables have corrected Item Total Correlation positive sign and $>0.3$ and alpha value Cronbach more than 0.6.

Thus, it can be stated that all indicators are good and have validity and reliability because the indicator is not too difficult and not too easy. Therefore, the psychometric properties of an instrument measure teachers' perceptions of teaching factory management, HR, workshops/labs, learning training, marketing promotions, products and services, industrial partnerships, and learning outcomes, presenting the value of reliability and validity of a questionnaire to be important so that other researchers confident with the quality of the data obtained later.

\section{CONCLUSION}

The question items in the teaching factory parameter variable are valid because: Corrected Item Total Correlation positive sign and $>0.3$. Thus, all question items from the dimensions of Management, Workshop/Laboratory, Learning Patterns, Marketing Promotion, Products/Services, HR, Industrial Relations, all indicators can measure all dimensions of the teaching factory parameter variable. On this basis, all items meet the validity requirements and will be maintained on the scale and used in further analysis. The calculation results show that Cronbach's alpha value of all dimensions has a value greater than 0.6 so that all dimensions on the variable are stated to have good reliability.

\section{REFERENCES}

[1] Sugiyono, S. "Qualitative and Quantitative Research Methodology R \& D." (2012).

[2] Litwin, Mark S. "Scaling and scoring." How to Measure Survey Reliability and Validity. Thousand Oaks, CA, USA: SAGE Publications Inc (1995): 47-52.

[3] Anderson, Terry, and Liam Rourke. "Using peer teams to lead online discussions." (2002).
[4] Turconi, G., M. Celsa, C. Rezzani, G. Biino, M. A. Sartirana, and C. Roggi. "Reliability of a dietary questionnaire on food habits, eating behaviour and nutritional knowledge of adolescents." European journal of clinical nutrition 57, no. 6 (2003): 753 763.

[5] Baltes, Paul B., Margret M. Baltes, Alexandra M. Freund, and Frieder R. Lang. The measurement of selection, optimization, and compensation (SOC) by self report: Technical report 1999. Max-PlanckInstitut für Bildungsforschung, 1999.

[6] Swanepoel, C. H., and J. J. Booyse. "Experience of imposed educational change by a heterogeneous group of teachers." South African Journal of Education 23, no. 2 (2003).

[7] Muchinsky, Paul M., Hendrik Jacobus Kriek, and Andries Magiel Gert Schreuder. Personnel psychology. International Thomson Publishing (Southern Africa), 1998.

[8] Edenborough, Robert. Using psychometrics: a practical guide to testing and assessment. Kogan Page Publishers, 1999.

[9] Kmet, Leanne M., Linda S. Cook, and Robert C. Lee. "Standard quality assessment criteria for evaluating primary research papers from a variety of fields." (2004).

[10] Lewis, BR, Snyder, CA \& Rainer, KR 1995. An empirical assessment of the Information Resources Management construct. Journal of Management Information Systems, 12, 1999-223

[11] Boudreau, Marie-Claude, David Gefen, and Detmar W. Straub. "Validation in information systems research: A state-of-the-art assessment." MIS quarterly (2001): 1-16.

[12] Welman, C., F. Kruger, and B. Mitchell. "Research methodology. What is environmental education (2005)? Cape Town: Oxford University Press."

[13] Knapp, Thomas R., and Ralph O. Mueller. "Reliability and validity of instruments." The reviewer's guide to quantitative methods in the social sciences (2010): 337-341.

[14] Huck, Schuyler W. Reading statistics and research. Pearson Education, 2012.

[15] Robinson, David G. A survey of probabilistic methods used in reliability, risk and uncertainty analysis: Analytical techniques 1. No. SAND-981189. Sandia National Labs., Albuquerque, NM (United States), 1998. 
[16] Lamoureux, Michael. "Tutorial on compressive sampling. Back to Exploration." In 2008 CSPG CSEG CWLS Convention Conference. 2008.

[17] Pallant, Julie. "Survival manual." A step by step guide to data analysis using SPSS 4 (2011).

[18] Fitzner, Karen. "Reliability and validity a quick review." The Diabetes Educator 33, no. 5 (2007): 775-780.

[19] Fisher Jr, W. "Reliability statistics. Rasch Meas Trans 1992; 6: 238." (2007).

[20] DeVellis, Robert F. "Classical test theory." Medical care (2006): S50-S59.

[21] Whitley, BE 2002. Principals of Research and Behavioral Science, Boston, McGraw-Hill

[22] Burns \& Groves. The practise of nursing research: appraisal, synthesis and generation of evidence. 6th ed. St. Louis, Mo.: Elsevier/Saunders, (2011).

[23] Cho, D. (1999). A study on ESL writing assessment: Intra-rater reliability of ESL

[24] Mardapi, Djemari. "Measurement of education assessment and evaluation." (2008).

[25] L.S. Streiner D, Shannon S. Predictive validity of the emergency physician and global job satisfaction instruments.Acad Emerg Med, 1998 